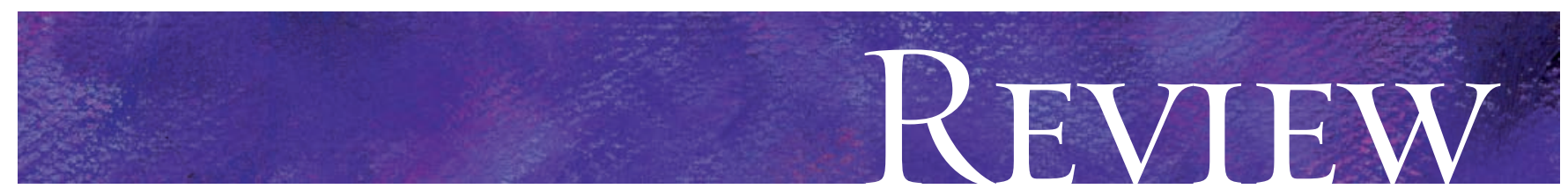

\title{
Summary of findings from the evaluation of a pilot medically supervised safer injecting facility
}

\author{
Evan Wood, Mark W. Tyndall, Julio S. Montaner, Thomas Kerr
}

$\infty \quad$ See related article page I395

\section{ABSTRACT}

In many cities, infectious disease and overdose epidemics are occurring among illicit injection drug users (IDUs). To reduce these concerns, Vancouver opened a supervised safer injecting facility in September 2003. Within the facility, people inject pre-obtained illicit drugs under the supervision of medical staff. The program was granted a legal exemption by the Canadian government on the condition that a 3-year scientific evaluation of its impacts be conducted. In this review, we summarize the findings from evaluations in those 3 years, including characteristics of IDUs at the facility, public injection drug use and publicly discarded syringes, HIV risk behaviour, use of addiction treatment services and other community resources, and drug-related crime rates. Vancouver's safer injecting facility has been associated with an array of community and public health benefits without evidence of adverse impacts. These findings should be useful to other cities considering supervised injecting facilities and to governments considering regulating their use.

CMAJ 2006;175(II):1399-404

M any cities are experiencing infectious disease and overdose epidemics as a result of illicit injection drug use,${ }^{1-4}$ an activity that is also associated with a number of negative community impacts, including public drug use. ${ }^{5,6}$ Despite these harms, innovative public health programs for reducing health and community concerns remain highly controversial in North America and other settings where HIV infection is spreading rapidly among injection drug users (IDUs). ${ }^{7-9}$

In Canada, Vancouver has been an epicentre of drugrelated harm during the last decade. ${ }^{10}$ In response, the affected community began advocating a medically supervised safer injecting facility where IDUs could inject pre-obtained drugs under the supervision of medical staff. ${ }^{11}$ Within the fa$\approx$ cility, IDUs are typically provided with sterile syringes and emergency care in the event of overdose, as well as primary care services and referral to addiction treatment. ${ }^{12}$ Such facilities exist in more than 2 dozen European cities and, more recently, in Sydney, Australia. ${ }^{12,13}$

Vancouver's safer injecting facility (Fig. I) was opened in September 2003 as a pilot study. ${ }^{13}$ The legal exemption by the federal government that allowed operation of the facility was limited to 3 years and was granted on the condition that an external 3-year scientific evaluation of its impacts be conducted. Given the controversial nature of the program, ${ }^{14}$ stakeholders agreed that all findings from the evaluation, including this report, should be externally peer-reviewed and published in the medical literature before dissemination. In this review we report on the 3 years' findings.

\section{Program and evaluation methods}

As described previously, ${ }^{13}$ the Vancouver safer injecting facility has I2 injection stalls where IDUs inject pre-obtained illicit drugs under the supervision of nurses. Nurses respond to overdoses and address other health needs (e.g., treating injection-site abscesses), and the facility has an addiction counsellor and support staff who seek to meet the needs of IDUs or refer them to appropriate community resources (e.g., housing services, addiction treatment). ${ }^{13}$

Although the best strategy for evaluating the safer injecting facility would be to randomly assign IDUs to either full access or no access to the program, interventional study designs for the evaluation of such facilities have been deemed unethical; ${ }^{15}$ thus, the evaluation of the Vancouver facility was structured primarily around prospective cohort studies involving IDUs who used the facility and those who did not. In accordance with the Transparent Reporting of Evaluations with Nonrandomized Designs (TREND) criteria for observational research, ${ }^{16}$ a detailed description of the evaluation

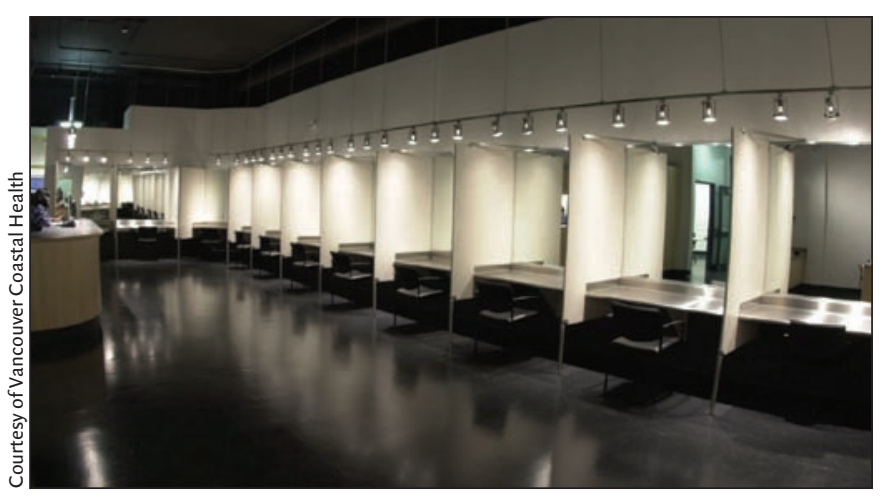

Fig. 1: Vancouver's medically supervised safer injecting facility. 
methods has been published. ${ }^{17}$ The evaluators were entirely external to facility operations, which are overseen by Vancouver Coastal Health, and the evaluation was supervised by a provincial steering committee and funded by Health Canada.

\section{Summary of findings}

\section{Characteristics of people using the safer injecting facility}

Before the safer injecting facility opened, a key concern was its ability to attract its target population. ${ }^{18}$ The facility's public health and community benefit would clearly be limited if it did not attract the IDUs who were at highest risk of healthrelated harms and those responsible for public order problems (e.g., public injection drug use). Identification of the characteristics of IDUs initiating use of the facility was helped by the existence of an ongoing prospective cohort study of IDUs operating in the community before the facility opened. This cohort has been described in detail. ${ }^{17,19}$ Thus, it was possible to examine drug use patterns in the community during the year before the opening of the facility and identify patterns that predicted subsequent initiation of use of the facility during the year after it opened.

Characteristics and behaviours were defined based on questionnaire data obtained immediately before the safer injecting facility opened, whereas the prevalence of use of the facility was ascertained based on the first questionnaire after the facility opened. In a community-recruited cohort of IDUs, $45 \%$ reported using the facility and, as shown in Fig. 2, the characteristics and drug-use behaviours that predicted initiation of use of the facility included lower age, public injection drug use, homelessness or unstable housing, daily heroin injection, daily cocaine injection and a recent nonfatal overdose..$^{20}$

Subsequent analysis of IDUs using the facility between Mar. Io, 2004, and Apr. 30, 2005, revealed that about 5000 unique IDUs used the facility during the first year of opera- tion. Heroin was used in about $40 \%$ of injections, cocaine in $30 \%$ of injections, and other illicit drugs, drug combinations or diverted pharmaceuticals in the remaining injections. ${ }^{21}$ In a survey of perceptions regarding their use of the facility, about $95 \%$ of IDUs using the facility reported high levels of satisfaction with the site and the staff. ${ }^{22}$

Examination of a random sample of 670 IDUs recruited from within the safer injecting facility between Dec. I, 2003, and July 30, 2004, demonstrated that the following factors were independently associated with daily use of the facility: daily heroin injection (odds ratio [OR] 3.44, 95\% confidence interval [CI] 2.50-4.73), homelessness (OR 2.4, 95\% CI r.63.6), not receiving methadone maintenance treatment (OR 2.I, 95\% CI I.44-3.I) and daily cocaine injection (OR 2.0, $95 \%$ CI I.4-2.8). ${ }^{23}$

Requiring help with injections was negatively associated with daily use of the facility (OR $0.6 \mathrm{I}, 95 \% \mathrm{CI} 0.43^{-0.86}$ ), a finding of concern, because this factor has been identified as an independent predictor of HIV incidence in the community. ${ }^{24}$ This finding implies that the rule prohibiting assisted injecting within the facility should be examined. It is noteworthy that local IDUs have begun outreach efforts to help teach safer injecting methods to those who need help with injections.

The above series of analyses demonstrated wide acceptance of the safer injecting facility within the local IDU community and showed that the facility attracted a particularly high-risk population. ${ }^{20,21,23}$

\section{Public order}

In anticipation of the facility's opening, a field survey protocol was developed to measure specified public order indicators within the ro city blocks that surround the facility. ${ }^{25}$ These indicators included number of publicly discarded syringes, public injection drug use, injection-related litter and the presence of suspected drug dealers. Because law enforce-

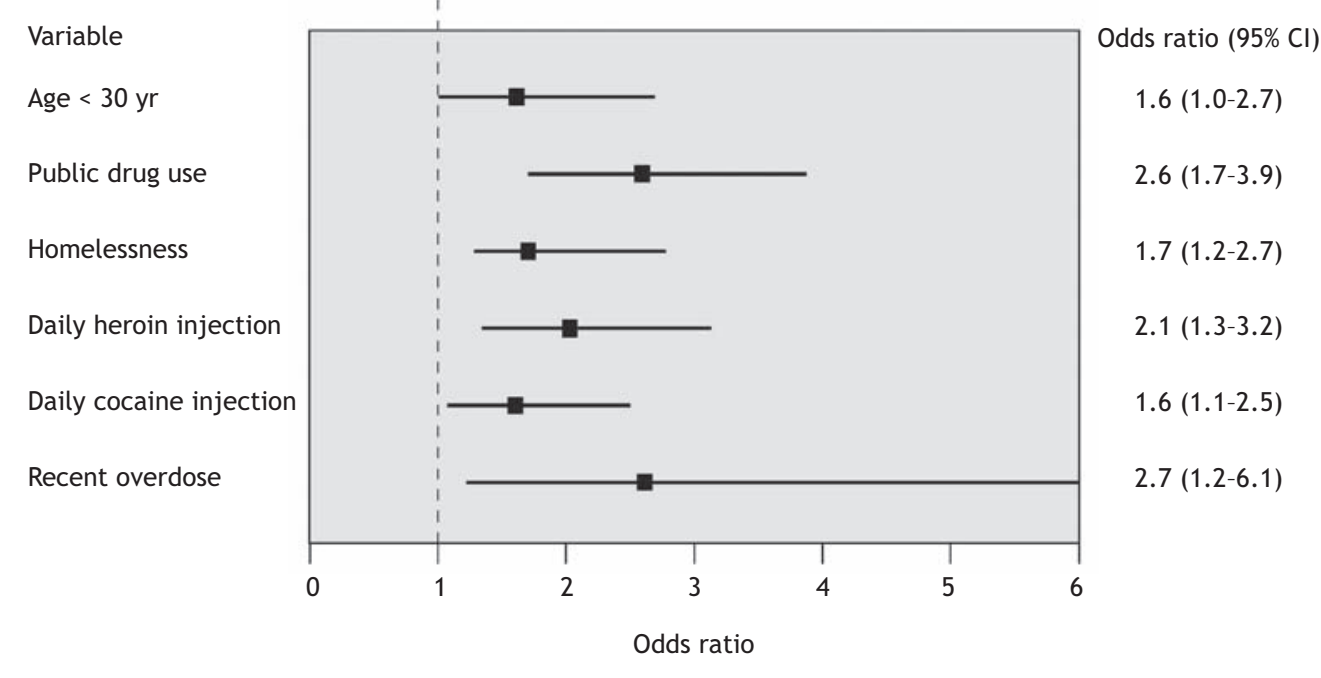

Fig. 2: Characteristics of injection drug users (IDUs) measured in the community before the Vancouver safer injecting facility opened, which predicted subsequent initiation of facility use. 
ment activities have an impact on the location of injection drug use, the total number of police patrols encountered during the hours of data collection was recorded to control for the potentially confounding effect of enforcement activities. The indicators were measured during the 6 weeks before and I2 weeks after the facility opened. This I8-week study period was selected to obtain sufficient follow-up evidence to provide statistical power while attempting to minimize the potential effect of seasonal changes in drug-use patterns, al-
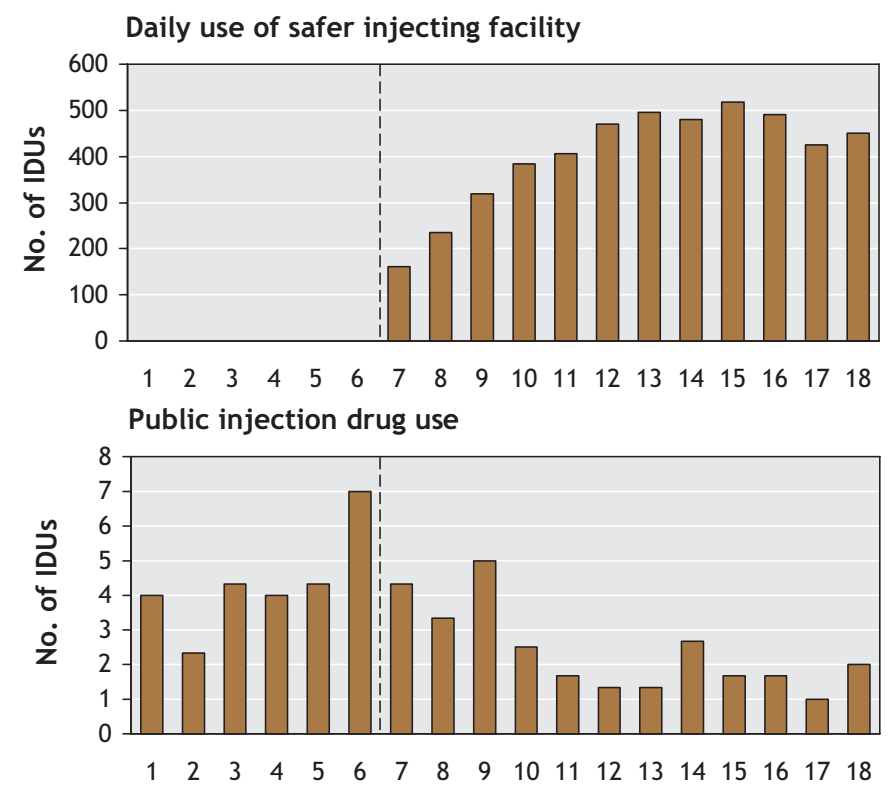

Publicly discarded syringes

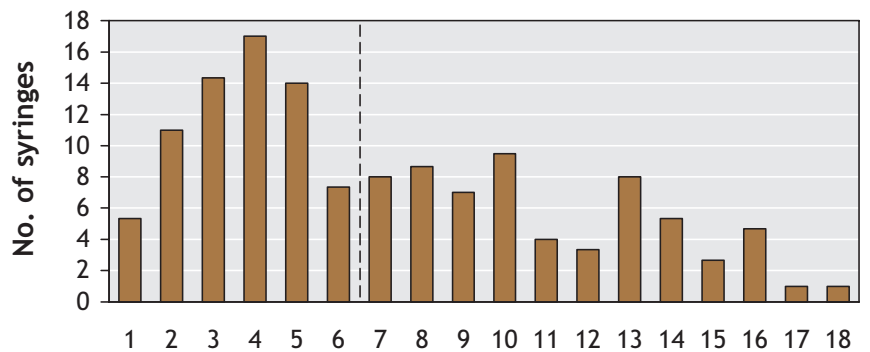

Injection-related litter

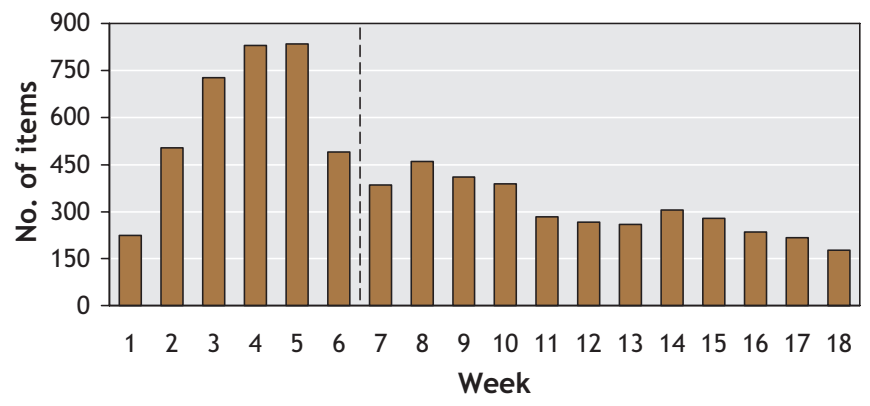

Fig. 3: Mean daily numbers of IDUs who visited the safer injecting facility, IDUs who injected in public, publicly discarded syringes and injection-related litter counted during the 6 weeks before and the 12 weeks after the facility opened. Dotted line represents opening of facility. Reproduced from Wood et al. ${ }^{25}$ though rainfall patterns were also adjusted for in the Poisson log-linear regression models that were used on the daily counts of the public-order indicators.

All measures of public disorder showed decreases in the wake of the facility's opening (Fig. 3). Regression models using parameter estimates showed a decline in the predicted mean number of public injections and publicly discarded syringes that coincided with the opening of the facility (Table I). As an external measure of the impact of the facility on public drug use, an examination of data from the city of Vancouver on the number of syringes discarded in the neighbourhood's outdoor safe disposal boxes revealed that the mean number of syringes safely discarded in each of the boxes also declined in the I2-week period after the facility opened ( $p<$ $0.00 I) .{ }^{25}$ Subsequent to this, police have continued to report a qualitative decline in public drug use. ${ }^{26}$

\section{Use of education services about safer injecting}

One of the greatest risk factors for HIV infection among IDUs in Vancouver has been the need for assistance with injections. ${ }^{24}$ Because lack of knowledge regarding safer injecting practices is a major factor contributing to the risk, ${ }^{27}$ education in this area was an important objective of the facility. To evaluate progress, 874 facility users were recruited between May 3I, 2003, and Oct. 22, 2004. More than 30\% of them reported receiving safer injecting education from nurses within the facility (e.g., how to inject oneself safely to avoid infection). Requiring help with injections at least once in the 6 months before the evaluation was one of the strongest independent predictors of receiving safer injecting education (OR 2.20, 95\% CI I.622.98).$^{28}$ Another study showed that IDUs who previously required help with injections no longer needed assistance as a result of education from nurses within the facility. ${ }^{29}$

\section{HIV risk behaviour and safer injecting practices}

Evaluation of the impact of the safer injecting facility on syringe sharing was undertaken by examining factors associated with this practice among community-recruited IDUs and by comparing rates of syringe sharing among regular versus irregular users of the facility. ${ }^{30}$ A potential conservative bias in

Table 1: Predicted daily mean measures of public order problems during the 6 weeks before and the 12 weeks after the opening of Vancouver's safer injecting facility*

\begin{tabular}{lcc}
\hline & \multicolumn{2}{c}{ Predicted daily mean no. $(95 \% \mathrm{Cl})$} \\
\cline { 2 - 3 } Measure & $\begin{array}{c}\text { Before the } \\
\text { facility opened }\end{array}$ & $\begin{array}{c}\text { After the } \\
\text { facility opened }\end{array}$ \\
\hline IDUs injecting in public & $4.3(3.5-5.4)$ & $2.4(1.9-3.0)$ \\
Publicly discarded syringes & $11.5(10.0-13.2)$ & $5.4(4.7-6.3)$ \\
Injection-related litter & $601(590-613)$ & $310(305-317)$ \\
\hline
\end{tabular}

Note: $\mathrm{Cl}=$ confidence interval, IDU = injection drug user.

*Parameter estimates from the unadjusted Poisson log-linear regression models were used to calculate the predicted means. Reprinted from Wood et al. ${ }^{25}$ 
these analyses stems from the fact that, as indicated in Fig. 2, users of the facility had a number of drug-use behaviours, such as daily cocaine injection, that have been associated with increased levels of syringe sharing. ${ }^{31}$ Nevertheless, as shown in Table 2, among IDUs followed between Dec. I, 2003, and June I, 2004, use of the facility was independently associated with reduced syringe sharing (OR 0.3, 95\% CI 0.I-0.8) in multivariable analyses.

Examination of data obtained before and after the safer injecting facility opened revealed that the rate of syringe sharing decreased after the facility opened and only among facility users. ${ }^{30}$ A subsequent analysis, which was restricted to facility users recruited between Mar. 22 and Oct. 22, 2004, demonstrated that greater exposure to the facility was associated with reduced syringe lending by HIV-infected IDUs and reduced syringe borrowing by HIV-negative IDUs. ${ }^{32}$

With respect to the risk of bloodborne bacterial infections, such as cellulitis and endocarditis, a study involving 760 facility users recruited between July I, 2004, and June 30, 2005, demonstrated that use of the facility was independently associated with other safe injection practices, including decreased reuse of syringes, increased use of sterile water and increased use of alcohol swabbing of injection sites. ${ }^{29}$

Table 2: Multivariable logistic regression of factors associated with syringe sharing*

\begin{tabular}{lcc}
\hline Factor & Adjusted OR $(95 \% \mathrm{Cl})$ & $p$ value \\
\hline Age (per year) & $0.95(0.92-0.98)$ & 0.01 \\
$\begin{array}{l}\text { Use of safer injecting } \\
\text { facility (yes v. no) }\end{array}$ & $0.30(0.11-0.82)$ & 0.02 \\
$\begin{array}{l}\text { Requiring help injecting } \\
\text { (yes v. no) }\end{array}$ & $2.95(1.57-5.55)$ & 0.01 \\
Bing drug use (yes v. no) & $2.04(1.02-4.08)$ & 0.04 \\
\hline Intercept (constant) & $(-0.79)$ & 0.19 \\
\hline
\end{tabular}

Note: $\mathrm{OR}=$ odds ratio, $\mathrm{Cl}=$ confidence interval.

*Model was adjusted for all variables found to be associated with syringe

sharing in univariable analyses at $p<0.05$.

Reprinted, with permission, from Kerr et al. ${ }^{30}$ (c) 2005 Elsevier.

\section{Referral for addiction treatment and other care}

An evaluation conducted between Mar. Io, 2004, and Apr. 30, 2005, demonstrated that the safer injecting facility serves as a referral centre for many community resources. More than 800 referrals were made per quarter, and about $40 \%$ of referrals were for various forms of addiction treatment. ${ }^{21}$ Because an addiction counsellor is on site at the facility and other facility staff refer IDUs to addiction services, an evaluation was undertaken to examine factors associated with more rapid entry into a detoxification program among facility users. ${ }^{33}$ Definition of this end point was based on linkage to a database maintained by Vancouver's 3 detoxification facilities, which offer medically monitored residential withdrawal services with on-site nursing and medical care. The study period considered each participant's recruitment date up until Mar. I, 2005. As shown in Table 3, at least weekly use of the facility (adjusted relative hazard [RH] I.72, 95\% CI I.25-2.38; $p=$ $0.00 \mathrm{I})$ and contact with the facility's addiction counsellor (adjusted RH I.98, 95\% CI I.26-3.I0; $p=0.003$ ) were independently associated with more rapid entry into a detoxification program. ${ }^{33}$ Of note, this study concluded that the increased uptake of detoxification services was not due to selection effects, because regular facility users had several baseline characteristics that have been shown to predispose to lower uptake of addiction treatment. ${ }^{34}$ These analyses suggested that amenities within the facility were responsible for increased uptake of addiction treatment among IDUs. In addition to addiction treatment, referrals were also commonly made to community health clinics, hospital emergency departments and housing services. ${ }^{21}$

\section{Overdoses}

Between Mar. I, 2004, and Aug. 30, 2005, nurses at the safer injecting facility responded to about I. 3 overdoses per Iooo injections. ${ }^{35}$ Heroin accounted for about $70 \%$ of the overdoses, cocaine for $15 \%$, and the injection of drug combinations (e.g., heroin with cocaine), methamphetamine or di-

Table 3: Univariable and multivariable Cox proportional hazard analyses of the time to entry into a detoxification program among 1031 IDUs after the safer injecting facility opened*

\begin{tabular}{lcccc}
\hline Variable & $\begin{array}{c}\text { Unadjusted relative } \\
\text { hazard }(95 \% \mathrm{Cl})\end{array}$ & $p$ value & $\begin{array}{c}\text { Adjusted relative } \\
\text { hazard }(95 \% \mathrm{Cl})\end{array}$ & $p$ value \\
\hline Homelessness† (yes v. no) & $1.43(1.07-1.91)$ & 0.015 & $1.42(1.06-1.90)$ & 0.019 \\
Binge drug use† (yes v. no) & $1.44(1.05-1.97)$ & 0.023 & $1.35(0.98-1.85)$ & 0.064 \\
Ever in treatmentł (yes v. no) & $2.70(1.56-4.65)$ & $<0.001$ & $2.43(1.41-4.22)$ & 0.002 \\
Weekly use of facility§ (yes v. no) & $1.84(1.34-2.52)$ & $<0.001$ & $1.72(1.25-2.38)$ & 0.001 \\
\hline Use of addiction counselling†§ (yes v. no) & $2.41(1.55-3.77)$ & $<0.001$ & $1.98(1.26-3.10)$ & 0.003 \\
\hline
\end{tabular}

Note: $\mathrm{Cl}=$ confidence interval, IDU = injection drug user.

*Use of a detoxification service was identified on the basis of database linkage. The model was adjusted for all variables that were significant $(p<0.05)$ in unadjusted analyses, including all variables shown, as well as residence in the neighbourhood of the facility (yes v. no). Participants who remained persistently out of a detoxification program were censored as of Mar. 1, 2005.

†ln the 6 months before the interview.

$\neq$ Current or past use of addiction treatment services.

§Data derived from database of safer injecting facility database; weekly use was determined according to the average use before the censoring or event date.

Reprinted, with permission, from Wood et al. ${ }^{33} \Subset 2006$ Massachusetts Medical Society. All rights reserved. 
verted pharmaceuticals accounted for the remainder. Although about $40 \%$ of cases required an ambulance call, $60 \%$ of overdoses were successfully managed by facility staff without the need for external support. Naloxone was administered in about $30 \%$ of cases of overdose. Despite the relatively high number of overdoses within the facility, there have been no overdose-related deaths. ${ }^{35}$

\section{Potential negative impacts}

Before the facility was opened, there were concerns that it would result in increased crime rates in the neighbourhood as a result of the migration of drug dealers and drug users toward the facility and subsequent increases in drug dealing and drug acquisition crime. ${ }^{36}$ The analysis of public order indicators described above showed that suspected drug dealing did not increase in the vicinity of the facility and that public drug use declined. ${ }^{25}$ In addition, police statistics during the year before versus the year after the facility opened showed that crime rates remained stable in the neighbourhood where the facility is located. Specifically, the facility's opening has not been associated with increases in charges for drug dealing or several markers of drug-related crime, including assaults, robbery and vehicle break-ins. ${ }^{37}$

Before the facility opened, there were also concerns that providing a safe and sterile place for injection drug use could reduce the likelihood that IDUs would seek addiction treatment and would result in increased rates of injection drug use. ${ }^{36}$ As indicated in the section on referral for addiction treatment and other care, use of the facility has been associated with an increased uptake of detoxification services, which suggests that the facility has not resulted in a reduced number of IDUs seeking addiction treatment. ${ }^{33}$ Similarly, comparing the I-year periods before and after the facility opened revealed no evidence that the provision of a safe and sterile place for injection drug use has resulted in increased rates of relapse into injection drug use or decreased rates of cessation of injection drug use in the community. ${ }^{38}$ Finally, an additional study involving all participants recruited into the cohort by Oct. 2I, 2005, demonstrated that the program has not been associated with increases in new initiates into injection drug use. ${ }^{39}$

\section{Discussion}

Evaluations of the Vancouver safer injecting facility have shown that the program has been successful in attracting IDUs in the community who have a number of characteristics associated with an increased risk of HIV infection and overdose, as well as IDUs who were more likely to inject drugs in public. ${ }^{20,23}$ In turn, there have been large reductions in public drug use, publicly discarded syringes and syringe sharing after the facility opened. ${ }^{25}$ Use of the facility has also been associated with increased uptake of detoxification services; ${ }^{33}$ the facility has been a central referral mechanism to a range of other community and medical resources and a key venue for education about safer injecting. ${ }^{28}$ Research has indicated that the facility has not resulted in increases in drug dealing in the facility's vicinity, ${ }^{25}$ in drug acquisition crime ${ }^{37}$ or in rates of new IDUs or relapse into injection drug use among former IDUs..$^{38,39}$

This report comes at a critical time: Canada's new prime minister and federal health minister both expressed reservations about the Vancouver safer injecting facility before the most recent Canadian federal election..$^{40}$ Subsequently, the application to extend for 3.5 years the exemption that allows for the legal operation of the facility was rejected by the health minister in favour of a shorter extension and a freeze on research into safer injecting facilities in other Canadian settings, despite recommendations from Health Canada that the 3.5-year extension be granted. ${ }^{41}$ The minister's decision to go against Health Canada's recommendation followed declarations of several national law enforcement bodies who, without providing any data, suggested that the facility has been unsuccessful. ${ }^{42,43}$ Although the federal health minister's justification was that "initial research has raised new questions, ${ }^{\prime 41}$ federal research funding of the evaluation was halted. In the wake of recent statements, ${ }^{41-44}$ it is important to stress that the benefits demonstrated in the evaluations of the Vancouver facility are largely consistent with reports from several European settings ${ }^{12}$ and Australia. ${ }^{45}$

The evaluations of the Vancouver safer injecting facility were limited by their observational nature, and hence all findings must be interpreted with this in mind. Nevertheless, studies to date have benefited from a number of unique methodological features that may have served to limit potential biases. There has also been consistency among a range of measures used to make inferences about the facility's clientele and its impact on public drug use and HIV risk behaviour. A further limitation of the evaluations, which can potentially be viewed as an indication of the facility's success to date, is that there have been too few HIV seroconversions and fatal overdoses among facility users to assess the impact of the facility on these outcomes.

In summary, the evaluations of the Vancouver safer injecting facility have documented a large number of health and community benefits, and there have been no indications of community or health-related harms. Although the effect of closing the facility is unknown, the above findings suggest a high potential for negative impacts on health and the community. This report should be useful to international agencies concerned about the impacts and legality of safer injecting facilities ${ }^{14,42,46,47}$ and to those in a large number of national and international settings currently debating the merits of such facilities as a strategy to address the injection drug use problem. ${ }^{4-52}$

This article has been peer reviewed.

From the British Columbia Centre for Excellence in HIV/AIDS, St. Paul's Hospital, and the Department of Medicine, Faculty of Medicine, University of British Columbia, Vancouver, BC (all authors)

Competing interests: None declared for Evan Wood, Mark Tyndall and Thomas Kerr. Julio Montaner has received educational grants from, served as an ad hoc advisor to or spoken at various events sponsored by Abbott Laboratories, Agouron Pharmaceuticals Inc., Boehringer Ingelheim Pharmaceuticals Inc., Borean Pharma AS, Bristol-Myers Squibb, DuPont Pharma, Gilead Sciences, GlaxoSmithKline, Hoffmann-La Roche, Immune Response Corporation, Incyte, Janssen-Ortho Inc., Kucera Pharmaceutical Company, Merck Frosst Laboratories, Pfizer Canada Inc., Sanofi Pasteur, Shire Biochem Inc., Tibotec Pharmaceuticals Ltd. and Trimeris Inc. 
Contributors: Evan Wood wrote the original draft of the manuscript and addressed the reviewer's comments. All of the authors contributed to the writing and revising of the manuscript and approved the final version.

Acknowledgements: We thank the participants in the evaluations of the Vancouver safer injecting facility and the staff of the Insite safer injecting facility, the Portland Hotel Society and Vancouver Coastal Health (Chris Buchner, David Marsh, Heather Hay). We also thank Aaron Eddie, Suzy Coulter, Megan Oleson, Peter Vann, Dave Isham, Steve Gaspar, Cristy Power, Will Small, Elisa Lloyd-Smith, Jo-Anne Stoltz, Calvin Lai, Deborah Graham, Caitlin Johnston and Steve Kain for their research and administrative assistance. The evaluations of the safer injecting facility were made possible by a financial contribution from Health Canada, although the views expressed herein do not represent the official policies of Health Canada.

\section{REFERENCES}

I. Strathdee SA, Galai N, Safaeian M, et al. Sex differences in risk factors for HIV seroconversion among injection drug users: a ten year perspective. Arch Intern Med 200I;I6I:I28I-8.

2. Des Jarlais DCP, Friedman SR, Hagan H, et al. Maintaining low HIV seroprevalence in populations of injecting drug users. JAMA I995;274:I226-3I.

3. Garfield J, Drucker E. Fatal overdose trends in major US cities: I990-I997. Addict Res Theory 2001;9:425-36.

4. Coffin PO, Galea S, Ahern J, et al. Opiates, cocaine, and alcohol combinations in accidental drug overdose deaths in New York City, 1990-98. Addiction 2003;98:739-47.

5. Doherty MC, Junge B, Rathouz $\mathrm{P}$, et al. The effect of a needle exchange program on numbers of discarded needles: a 2-year follow-up. Am JPublic Health 2000;90:936-9.

6. Dovey K, Fitzgerald J, Choi Y. Safety becomes danger: dilemmas of drug-use in public space. Health Place 2001;7:319-31.

7. Needle-exchange programmes in the USA: Time to act now. Lancet 1998;351:75.

8. Skolnick AA. "Collateral casualties" climb in drug war. JAMA 1994;271:1636-9.

9. Kerr T, Kaplan K, Suwannawong P, et al. The Global Fund to Fight AIDS, Tuberculosis and Malaria: funding for unpopular public-health programmes. Lancet 2004; 364:II-2.

Io. Strathdee SA, Patrick DM, Currie SL, et al. Needle exchange is not enough: lessons from the Vancouver injecting drug use study. AIDS I997;II:F59-65.

II. Kerr T, Palepu A. Safe injection facilities in Canada: Is it time? CMAJ 200I; 165 (4):436-7.

I2. Dolan K, Kimber J, Fry C, et al. Drug consumption facilities in Europe and the establishment of supervised injecting centres in Australia. Drug Alcohol Rev 2000;19:337-46.

I3. Wood E, Kerr T, Montaner JS, et al. Rationale for evaluating North America's first medically supervised safer injecting facility. Lancet Infect Dis 2004;4:30I-6.

I4. Gandey A. US slams Canada over Vancouver's new drug injection site. CMAJ 2003;I69(I0):1063.

I5. Christie T, Wood E, Schechter MT, et al. A comparison of the new Federal Guidelines regulating supervised injection site research in Canada and the Tri-Council Policy Statement on Ethical Conduct for Research Involving Human Subjects. Int J Drug Pol 2003;15:66-73.

I6. Des Jarlais DC, Lyles C, Crepaz N. Improving the reporting quality of nonrandomized evaluations of behavioral and public health interventions: the TREND statement. Am J Public Health 2004;94:36I-6.

I7. Wood E, Kerr T, Buchner C, et al. Methodology for evaluating Insite: Canada's first medically supervised safer injection facility for injection drug users. Harm Reduct $J$ 2004;I:9.

I8. Wente M. This quick fix won't work. Globe and Mail [Toronto] 2002 Nov I9;Sect A:23

I9. Wood E, Tyndall MW, Spittal PM, et al. Unsafe injection practices in a cohort of injection drug users in Vancouver: Could safer injecting rooms help? CMAJ 200I; I65(4):405-I0.

20. Wood E, Tyndall MW, Li K, et al. Do supervised injecting facilities attract higherrisk injection drug users? Am J Prev Med 2005;29:126-30.

2I. Tyndall MW, Kerr T, Zhang R, et al. Attendance, drug use patterns, and referrals made from North America's first supervised injection facility. Drug Alcohol Depend 2006;83:193-8.

22. Petrar S, Kerr T, Tyndall M, et al. Injection drug users' perceptions regarding use of a medically supervised safer injecting facility. Addict Behav 2006 Aug 2I; [Epub ahead of print]

23. Wood E, Tyndall MW, Qui Z, et al. Service uptake and characteristics of injection drug users utilizing North America's first medically supervised safer injecting facility. Am J Public Health 2006;96:770-3.

24. O'Connell J, Kerr T, Li K, et al. Requiring help injecting independently predicts incident HIV infection among injection drug users. J Acquir Immune Defic Syndr 2005;40:83-8.
25. Wood E, Kerr T, Small W, et al. Changes in public order after the opening of a medically supervised safer injecting facility for illicit injection drug users. CMAJ 2004;I7I(7):73I-4.

26. Fewer addicts shooting up on streets since injection site opened: police. Nanaimo Daily News 2003 Nov I8; Sect A:5.

27. Wood E, Spittal PM, Kerr T, et al. Requiring help injecting as a risk factor for HIV infection in the Vancouver epidemic: implications for HIV prevention. Can J Public Health 2003;94:355-9.

28. Wood E, Tyndall M, Stoltz J, et al. Safer injecting education for HIV prevention within a medically supervised safer injecting facility. Int I Drug Pol 2005:I6:28I-4. Available: www.communityinsite.ca/pdf/hiv-education.pdf (accessed 2006 Oct Io).

29. Stoltz J, Wood E, Small W, et al. Changes in injecting practices associated with use of a medically supervised safer injection facility. Proceedings of the I7th International Conference on the Reduction of Drug Related Harm; 2006 Apr 30-May 4 Vancouver.

30. Kerr T, Tyndall M, Li K, et al. Safer injection facility use and syringe sharing in injection drug users. Lancet 2005;366:316-8.

31. Tyndall MW, Currie S, Spittal P, et al. Intensive injection cocaine use as the primary risk factor in the Vancouver HIV-I epidemic. AIDS 2003;17:887-93.

32. Wood E, Tyndall M, Stoltz J, et al. Factors associated with syringe sharing among users of a medically supervised safer injecting facility. Am J Infect Dis 2005;1:50-4. Available: www.scientificworld.net/fulltext/ajid/ajidı150-54.pdf (accessed 2006 Oct Io).

33. Wood E, Tyndall MW, Zhang R, et al. Attendance at supervised injecting facilities and use of detoxification services. NEngl J Med 2006;354:2512-4.

34. Wood E, Li K, Palepu A, et al. Sociodemographic disparities in access to addiction treatment among a cohort of Vancouver injection drug users. Subst Use Misuse 2005;40:1153-67.

35. Kerr T, Tyndall M, Lai C, et al. Drug-related overdoses within a medically supervised safer injecting facility. Int J Drug Pol. In press.

36. Bula F. Drug plan waste of resources, city told: more drug users will come here, U.S. official warns. Vancouver Sun 2002 Nov 2I; Sect AI.

37. Wood E, Tyndall MW, Lai C, et al. Impact of a medically supervised safer injecting facility on drug dealing and other drug-related crime. Subst Abuse Treat Prev Policy 2006;I:I3.

38. Kerr T, Stoltz JA, Tyndall M, et al. Impact of a medically supervised safer injection facility on community drug use patterns: a before and after study. BMJ 2006;332:220-2.

39. Kerr T, Tyndall M, Zhang R, et al. Circumstances of first injection among illicit drug users accessing a medically supervised safer injecting facility. Am J Public Health. In press.

40. Election may have doomed Victoria safe-injection site. Victoria Times-Colonist 2006 Feb 9; Sect A4.

4I. No new injection sites for addicts until questions answered says Minister Clement [press release]. Ottawa: Health Canada; 2006 Sept I. Available: www.hc-sc.gc.ca lahc-asc/media/nr-cp/2006/2006_85_e.html (accessed 2006 Sept 26).

42. International Narcotics Control Board. Report of the International Narcotics Control Board for 2003. Vienna: The Board; 2003. Available: www.incb.org/incb/en lannual_report_2003.html (accessed 2006 Sept 26).

43. CBC News. Police group takes aim at Vancouver safe injection site. 2006 Sept $\mathrm{r}$. Available: www.cbc.ca/canada/british-columbia/story/2006/og/or/bc-police-sis .html (accessed 2006 Sept 26)

44. Royal Canadian Mounted Police. RCMP responds to media reports concerning supervised injection site reviews [press release]. 2006 Aug 28. Available: www.rcmp .ca/news/2006_08_28_e.htm (accessed 2006 Sept 26).

45. MSIC Evaluation Committee. Final report of the evaluation of the Sydney medically supervised injecting centre. Sydney: MSIC Evaluation Committee; 2003. Available: www.sydneymsic.com/pdf/FinalReport.pdf (accessed 2006 Sept 26).

46. Yamey G. UN condemns Australian plans for "safe injecting rooms." BMJ 2000; 320:667.

47. Malkin I, Elliott R, McRae R. Supervised injecting facilities and international law. J Drug Issues 2003;33:539-78.

48. Strang J, Fortson R. Supervised fixing rooms, supervised injectable maintenance clinics - Understanding the difference. BMJ 2004;328:102-3.

49. Wright NM, Tompkins CN. Supervised injecting centres. BMJ 2004;328:100-2.

50. Green TC, Hankins CA, Palmer D, et al. My place, your place, or a safer place: the intention among Montreal injecting drug users to use supervised injecting facilities. Can J Public Health 2004;95:II0-4.

5I. Kimber J, Dolan K, van Beek I, et al. Drug consumption facilities: an update since 2000. Drug Alcohol Rev 2003;22:227-33.

52. A second chance for the UK to reduce drug-misuse deaths. Lancet 2006;367:1792.

Correspondence to: Dr. Evan Wood, Division of Epidemiology and Population Health, BC Centre for Excellence in HIV/AIDS, 608-I08I Burrard St., Vancouver BC V6Z IY6; fax 604 806-9044; ewood@cfenet.ubc.ca 